\title{
Individual and class-level factors for students' management of homework environment: The self-regulation perspective
}

\author{
Jianzhong $X \mathbf{u}^{1,2}$ iD \\ Accepted: 2 December 2021 \\ (c) The Author(s), under exclusive licence to Springer Science+Business Media, LLC, part of Springer Nature 2021
}

\begin{abstract}
The present study investigated the predictive effects of clusters of variables on homework environment management based on the data from 3018 students in Grade 8. These clusters included: background variables, homework characteristics, adult support and monitoring, homework purposes, goal orientations, and contextual control. At the individual level, management of homework environment was significantly related to at least one variable from each of the six clusters. Specifically, it was associated negatively with time spent watching TV, and positively with prior achievement, homework interest, homework quality, family help, teacher feedback, academic purpose, self-regulatory purpose, mastery-approach, and help seeking. Additionally, males managed homework environment less frequently than females. Finally, management of homework environment was positively related to homework quality at the class level.
\end{abstract}

Keywords Environmental control · Environmental structuring $\cdot$ Homework $\cdot$ Regulation of study environment $\cdot$ Selfregulation $\cdot$ Study environment management

\section{Introduction}

Commonly viewed as "tasks assigned to students by school teachers that are meant to be carried out during nonschool hours" (Cooper, 1989, p. 7), homework is a widespread, century-old instructional activity in many countries (Corno, 2000; Fan et al., 2017). Homework is frequently completed amid multiple competing activities at home or home-like environment, with less adult monitoring and structure than classwork (Corno \& Xu, 2004; Xu \& Corno, 1998; Yang et al., 2016). Therefore a critical challenge facing students is to manage their homework environment so that it is conducive to homework completion.

Students' management of homework environment can be defined as deliberately selecting and structuring the study environment to help themselves stay focused on their homework. Yet, despite research showing that students' management of homework environment is associated negatively

Jianzhong Xu

jx18@colled.msstate.edu; jianzhongxu18@gmail.com

1 Department of Counseling, Educational Psychology, and Foundations, Mississippi State University, P.O. Box 9727, Mississippi State, MS 39762, USA

2 Faculty of Education, University of Macau, Macau, China with homework distraction (Xu, 2010, 2015), and positively with homework completion and student achievement (Yang \& Xu, 2015; Zimmerman \& Kitsantas, 2005), little research has focused on systematically studying factors that affect students' management of homework environment.

Consequently, it is critically important to examine empirical models of homework environment management for both theoretical and practical reasons. First, as noted by Pintrich (2004), the control of study environment (compared with controlling and regulating cognition, motivation, cognition, and behavior) is more challenging, as it is not usually under an individual's direct control. Yet, few empirical research studies have investigated an individual's personal control over the study or work environment (Du et al., 2015; Lee \& Brand, 2010; Samani et al., 2017). Thus, our study has important theoretical implications for management of study and work environment, with homework environment in particular.

In practical terms, the focus on homework environment management is timely, as the SARS-CoV-2 pandemic has led to an unprecedented massive shift from conventional faceto-face education to online education (Bao, 2020). Many students are more likely to struggle to complete traditional or online homework during the SARS-CoV-2 pandemic, due to the digital divide, precarious housing situations, and 
other challenges associated with finding quiet and orderly surroundings for studying (Beaunoyer et al., 2020; Van Lancker \& Parolin, 2020).

The present study was informed by extant literature on homework environment management. It included the selfregulation perspective and empirical findings pertaining to factors that might affect students' management of homework environment.

\section{The Self-Regulation Perspective and Empirical Findings}

One important aspect of self-regulation is environmental structuring (Purdie \& Hattie, 1996; Zimmerman, 1998, 2008), managing and controlling study environment (Pintrich, 1999, 2004; Schunk, 2005), or environmental control (Corno, 2000). Regardless of the terms used by different researchers, this aspect of self-regulation entails students' initiative to arrange, manage, or control their immediate environment to facilitate their ability to complete a task (e.g., by preventing or reducing potential distractions; Corno, 2000; Pintrich, 2004; Wolters, 1999; Xu, 2012; Zimmerman, 2008). Zimmerman (1998), for example, conceptualized environmental structuring as selecting, creating, or arranging an effective setting to facilitate an individual's intention to complete an achievement-related task.

Pintrich (2004), in his model of self-regulation, identified four aspects of self-regulation (cognition, motivation, behavior, context) and, for each aspect, four phases of selfregulation (forethought, monitoring, control, reflection). Specifically, study environment regulation was viewed as a significant component of contextual regulation, involving students' initiatives to regulate or control relevant features of the environment to facilitate and optimize learning (e.g., finding a distraction-free location for studying). Conceptualized as a significant aspect of self-regulation or a core regulatory mechanism, study environment management can lead to various positive outcomes, including increases in selfefficacy, cognitive strategy use, effort, persistence, course performance, grade point average, and student satisfaction (Cooper \& Corpus, 2009; Li, 2019; Puzziferro, 2008; Sitzmann \& Ely, 2011).

The self-regulation perspective, along with related findings pertaining to homework environment management, suggests that six clusters of variables may affect environmental structuring, regulation, or management. These clusters include: (a) background variables, (b) homework characteristics, (c) adult support and monitoring, (d) homework purposes, (e) goal orientations, and (f) contextual control.

First, as the self-regulation perspective postulates that individual differences can affect students' attempts at self-regulation (Pajares, 2002; Tas et al., 2016; Zimmerman, 2008), homework environment management may be influenced by student background variables, including prior achievement, gender, and parent education. Students' prior achievement can affect their beliefs about their capabilities to regulate their learning (Pajares, 2002; Wigfield et al., 2004). Girls, compared with boys, report greater use of environmental structuring for optimal learning (e.g., doing homework and test preparation; Cleary, 2006; Li, 2019; Pajares, 2002). Although parent education has not been associated with homework environment management in previous studies (Xu, 2012; Xu \& Corno, 2006), it would be important to control for parent education in our study.

Second, as self-regulation is a self-directed and effortful process, students who are interested in an activity and view it as having high quality are more likely to apply self-regulation strategies (Bempechat, 2019; Kitsantas \& Zimmerman, 2009; Schunk, 2005; Tas et al., 2016). Hence, management of study environment as one important aspect of self-regulation is likely to be affected by task characteristics, including task interest (homework interest) and task quality (homework quality). This is, to some extent, supported by findings that students' homework interest is positively related to management of homework environment (Xu, 2012), and that homework quality is positively associated with homework self-regulation components (Tas et al., 2016).

Third, as the self-regulation perspective posits that sociocultural differences (e.g., teaching and family practices) could affect students' attempts at self-regulation (e.g., to help inform and guide their learning practices; Brown et al., 2016; Wolters, 2011; Zimmerman, 2008), homework environment management can be influenced by adult support and monitoring, including teacher feedback and family homework help. Related prior findings have provided empirical support regarding the importance of including this cluster of variables, in that students' management of homework environment is positively associated with teacher feedback $\mathrm{Xu}$, 2012) and family homework help (Xu, 2012; Xu \& Corno, 2006).

Fourth, as self-regulation is a purposeful, self-directed, effortful, and context-specific process, students who consider an activity as useful, relevant, and worthwhile tend to apply self-regulation strategies more frequently (e.g., planning and monitoring; Berger \& Karabenick, 2011; Schunk, 2005; Zimmerman, 1998). Hence, management of the study environment as a core component of self-regulation (Pintrich, 2004) is likely to be affected by homework purposes as perceived by students (e.g., to help them better understand course material). This argument is substantiated by prior findings that students' management of homework environment is significantly associated with homework purposes (Xu, 2011, 2012).

Fifth, achievement goal orientations can influence selfregulation, by directing and guiding students towards the use of self-regulatory processes (e.g., self-monitoring; 
Cellar et al., 2011; DeShon \& Gillespie, 2005; Pintrich, 2000). Although the relationship between performanceapproach and self-regulation is more variable (e.g. due to its emphasis on an external referent), self-regulation can be enhanced by the adoption of mastery-approach as students will be more likely to put forth an effort and persist in achievement-related activities (e.g., managing effort and time; Pintrich, 2000) when they set the goal of learning, growth, and self-improvement (Cellar et al., 2011; Pintrich, 1999). Thus, management of study environment can be shaped by students' goal orientations towards an achievement-related activity (e.g., homework), particularly regarding the adoption of mastery-approach. The importance of goal orientations in homework environment management is further substantiated by empirical findings demonstrating reciprocal relationships between achievement goals on the one hand, and achievement and interest on the other hand (Scherrer et al., 2020). Additionally, homework environment management is positively associated with prior achievement and homework interest (Xu, 2012).

Sixth, the self-regulation model developed by Pintrich (2004) posits that management of study environment is affected by help seeking, because it "involves contextual control. .. the procurement of help from others in the environment" (p. 398). Although no previous studies have been conducted with elementary and secondary school students, help seeking is positively related to college students' management of online homework environment (Du, 2016; Du et al., 2015). Additionally, unlike other academic tasks (such as coursework), homework typically occurs in the middle of other competing activities. Hence, it would be important to include time spent watching TV as another aspect of contextual control (or the lack of contextual control) that may influence students' management of homework environment. This is supported by a previous finding that time spent on homework is negatively related to homework environment management (Xu, 2012).

\section{Gaps in Prior Research}

The self-regulation perspective (Kitsantas \& Zimmerman, 2009; Schunk, 2005; Pintrich, 2000, 2004; Wolters, 2011; Zimmerman, 2008) suggests that the aforementioned six clusters of variables may influence students' management of homework environment. However, previous homework research has not yet explicitly examined the influence of one cluster of variables - goal orientations-on students' management of homework environment. Consequently, it would be important to incorporate goal orientations in our study, as students are more likely to put forth effort and persevere with achievement-related activities when they have high academic goal commitment (Postigo et al., 2021; Tang et al., 2021) and when they focus on their effort, progress, and self-improvement (Cellar et al., 2011; DeShon \& Gillespie, 2005; Pintrich, 1999). Such study would be important because achievement goals are reciprocally related to achievement and interest (Scherrer et al., 2020), and because students' management of homework environment is positively associated with prior achievement and homework interest (Xu, 2012).

Second, although no study that we are aware of has explicitly linked perceived homework quality to homework environment management, previous research has indicated that perceived homework quality positively influences homework self-regulation, homework effort, homework completion, and student achievement (Rosário et al., 2018; Stoeger \& Ziegler, 2011; Trautwein \& Lüdtke, 2009). These findings imply that homework environment management may be positively related to perceived homework quality, particularly as (a) homework quality is positively correlated with scores on Homework Management Scale (HMS; Xu, 2016) or the scale adapted by Tas et al. (2016), and as (b) Homework Environment Management is one of the five scales that is positively related to other four subscales (i.e., managing time, monitoring motivation, controlling emotion, and handling distraction; Xu \& Corno, 2006; Yang \& Xu, 2015). Hence, it would be important to include homework quality as another variable in the cluster of homework characteristics (i.e., along with homework interest) in our study.

Finally, much of what we have learned about students' management of homework environment has been derived from studies using a domain-general approach (e.g., Xu, 2012; Xu \& Corno, 2006). Given the call to adopt a domainspecific approach to homework (e.g., homework effort; Trautwein et al., 2006; Xu, 2015), there is a need to investigate homework environment management in one main achievement domain - math - for the following reasons. First, math plays a highly important role in the development of STEM learning and career aspirations (León et al., 2015). Second, compared with tasks in other achievement domains, students often experience math problems as particularly challenging and wearisome (Hagger et al., 2010). As a result, more effort and higher self-regulation are required for math learning (Marsh et al., 2016; Xu, 2021). Furthermore, math is an achievement domain with a high demand for homework across different countries (Kitsantas et al., 2011; Xu, 2015).

\section{The Present Study}

To address the above gaps in extant literature, the goal of our study was to investigate empirical models of students' management of math homework environment. Specifically, we implemented a multilevel research model as a conceptual framework to examine students' management of math homework environment at two levels: the student and the class levels. 
We investigated two sets of research questions and hypotheses. The first set of research questions focused on the individual level. Is homework environment management related to the six clusters of variables (background variables, homework characteristics, adult monitoring, homework purposes, goal orientations, and contextual control)? Consistent with the self-regulation perspective (Pintrich, 2004; Zimmerna, 2008) and previous research findings (Xu, 2012), we hypothesized that students' management of homework environment would be positively related to prior achievement, but unrelated to parent education. Additionally, in accordance with the self-regulation perspective and the prior study (Xu, 2012), we hypothesized that students' management of homework environment would be associated positively with teacher feedback, family help, and homework interest, but negatively with time spent watching TV.

As the perceived homework quality can positively influence students' homework motivation (Trautwein \& Lüdtke, 2009; Trautwein et al., 2006), which may in turn lead them to have more initiative to regulate their study environment, we hypothesized that students' management of homework environment would be positively associated with the perceived homework quality. Furthermore, in accordance with the self-regulation perspective (Pintrich, 1999, 2004) and related studies (Cellar et al., 2011; Payne et al., 2007), we hypothesized that students' management of homework environment would be positively related to help seeking and mastery-approach, but not related to performance-approach. As students' management of homework environment is positively related to learning-oriented reasons ( $\mathrm{Xu}, 2012)$, and as learning-oriented reasons can be further differentiated into academic and self-regulatory purposes for math homework (Sun et al., 2020), we hypothesized that students' management of homework environment would be positively associated with academic and self-regulatory purposes.

Meanwhile, as management of homework environment is negatively associated with peer-oriented reasons, yet unrelated to adult-oriented reasons (Xu, 2012), and as the scores on these two subscales are not empirically distinguishable with respect to math homework, we did not have a hypothesis regarding the relationship between approval-seeking purpose and management of homework environment. Furthermore, we did not have a hypothesis relating to gender differences, as the finding from a prior study (Xu, 2012) is inconsistent with related literature on environmental structuring (Pajares, 2002; Zimmerman \& Martinez-Pons, 1990).

The second set of research questions concerned the class level. Is management of homework environment related to homework interest, perceived homework quality, teacher feedback, and parent education at the class level? We incorporated these class-level variables because the development and adoption of self-regulatory strategies could be shaped by the academic and social contexts of assigning and doing homework at the class level (shared homework characteristics, and shared teacher and parent expectations; Corno \& Mandinach, 2004; Xu \& Wu, 2013). Specifically, we examined the degree to which homework environment management was related to homework characteristics shared by students in a class - their assessments of homework interest and the quality of homework. Additionally, we investigated the extent to which homework environment management was associated with shared parent and teacher expectations-parent education and teacher feedback. Consistent with a prior study (Xu, 2012), we hypothesized that, at the class level, homework environment management would be positively associated with homework interest, yet unrelated to parent education and teacher feedback. Furthermore, congruent with the prior finding (Xu, 2012) as well as our hypothesis at the individual level, we predicted that management of homework environment would be positively correlated with perceived homework quality and interest at the class level.

\section{Method}

\section{Participants and Procedure}

Participants were 3018 students in grade 8 (100\% Han nationality; $45.6 \%$ female; 96 classes). The mean participant age was $13.7 \pm 0.4$ years. Eight graders, on the verge of making the transition to high school, have extensive experience managing their environment while doing math homework. Additionally, as students move from elementary to middle and high schools, their attitudes and initiative play an increasingly significant role in homework completion and academic achievement (Cooper et al., 1998; $\mathrm{Xu}, 2008)$.

In many parts of China, public schools are classified into two types: regular schools and key schools. Regular schools typically enroll about $85-90 \%$ of students with a wide spectrum of academic performance, while key schools enroll about $10-15 \%$ of higher-achieving students, based on academic awards and standardized test scores. The key schools are provided with more educational resources and staffed with better-qualified teachers.

To counter the concern that homework research is frequently conducted on middle-class students (Cooper et al., 1998; Sun et al., 2021), we recruited students from varied socioeconomic backgrounds. In doing so, our study focused on average-achieving students from eight regular public schools (rather than key schools) from three regions in China (central, southeastern, and southwestern). Our goal was to include approximately 100 classes for multilevel analysis, as a small sample size at level two (i.e., 50 or less) may result in biased estimates of the second-level standard errors (Maas \& Hox, 2005). As a result, eight schools were randomly 
selected from 19 regular public schools that volunteered for our study, which resulted in 3018 students nested within 96 classes. Mothers of study participants, on average, completed 10.6 years of education, and while fathers completed 11.4 years, which was quite similar to the mean education level of 10.8 years for the Chinese working-age population (aged 16 to 59 years).

Concerning math homework assignments, over three quarters of participants (76.9\%) did math assignments four or more days a week. Additionally, they spent a mean of $34.1 \mathrm{~min} \pm 24.7$ on math assignments daily. These practices are largely comparable with related homework research in China (Xu et al., 2015).

The current investigation was approved by the Institutional Review Board of a local university in China. In line with the tenets of Helsinki Declaration, we obtained informed consent from parents as well as informed assent from students. Several research assistants administered the surveys in regular classes, while teachers were requested to step out of their classrooms. In addition, math teachers or other school staff did not have access to the survey data. Overall, the student participation rate was $88.7 \%$.

\section{Measures}

With exception of prior math grades, all of the measures in our study were based on students' self-report at the end of October, 2017, after they had some experience with math homework at this grade level. Table 1 displays items from each multi-item scale, along with respective response categories and reliability coefficients.

Parent Education Students were asked about their mother's and father's education level. Their responses were coded in years: elementary school (6), middle school (9), high school (12), some college (14), college graduate (16), some graduate school (18), and graduate degree (19). A variable named "parent education" was then created by averaging father's education and mother's education.

Prior Math Grade Prior math knowledge was measured by obtaining participants' math grades from teachers' school logs completed at the end of the prior school year (i.e., Grade 7). The grades were based on a 5-point letter system, ranging from $\mathrm{A}$ (excellent) to $\mathrm{F}$ (fail). They were coded as $A$ (5 points), $B$ (4 points), $C$ ( 3 points), $D$ ( 2 points), and $F$ (1 point).

Family Help Students reported how often parents helped them with math homework assignments. Responses contained never (1), rarely (2), sometimes (3), often (4), and routinely (5).
Teacher Feedback Based on extant homework studies (Xu \& Wu, 2013; Yang et al., 2016), this scale contained three statements to measure the degree to which teachers collected and checked math homework assignments (see an example of this scale, along with reliability coefficients in Table 1).

Homework Purpose Homework purpose included three dimensions-academic, self-regulatory, and approvalseeking purposes-based on the Math Homework Purpose Scale (MHPS; Sun et al., 2020). Four items measured academic purpose, regarding reinforcement of math learning. Three items measured self-regulatory purpose, regarding promoting self-discipline and responsibility. Three items focused on approval-seeking purpose, regarding obtaining approvals from adults and classmates. Our justification for using the MHPS, not a crossdomain Homework Purpose Scale (HPS; Xu, 2011) used in the previous study (Xu, 2012), is that our present study adopted a domain-specific approach to homework environment management.

Homework Goal Orientation This scale consisted of mastery- and performance-approaches, based on the Homework Goal Orientation Scale (HGOS; Sun et al., 2019). Sun et al. (2019), in their validation study involving secondary students, reported that mastery- and performance-approaches were empirically distinguishable (RMSEA $=.012$; $\mathrm{SRMR}=.020 ; \mathrm{CFI}=.999)$. For our current investigation, the same four items assessed students' adoption of masteryapproach relating to math assignments. The same three items assessed students' adoption of performance-approach relating to math assignments.

Homework Interest This scale included four statements to measure math homework interest, based on extant literature and previous homework studies (Wigfield \& Cambria, 2010; Yang et al., 2016). It assessed the extent to which students enjoyed math homework.

Perceived Homework Quality This scale contained four statements to assess perceived quality of math assignments (Xu, 2016; Xu et al., 2021). It focused on the extent to which math homework assignments were selected, prepared, and integrated into math lessons to help students understand and learn math concepts.

Help Seeking Drawn from literature on adaptive help seeking (Duncan \& McKeachie, 2005: Karabenick, 2003) and related homework research (e.g., Du et al., 2016), this scale contained five statements to assess students' initiative to seek help from adults (teachers and parents) and peers while working on math homework. 
Table 1 Multi-item scales and reliability coefficients

\begin{tabular}{|c|c|c|c|}
\hline Scales & Items & $\alpha$ & $\omega$ \\
\hline Teacher feedback ${ }^{a}$ & $\begin{array}{l}\text { "How much of your math HW is collected by math teacher?" } \\
\text { "How much of your math HW is checked by math teacher?" } \\
\text { "How much of your assigned math HW is graded by teachers?" }\end{array}$ & .70 & .71 \\
\hline Academic purpose $^{\mathrm{b}}$ & $\begin{array}{l}\text { "Doing math HW helps understand what's going on in class" } \\
\text { "Doing math HW helps me prepare for the next lesson" } \\
\text { "Doing math HW gives me opportunities to learn from classmates" } \\
\text { "Doing math HW helps me get a good grade" }\end{array}$ & .76 & .76 \\
\hline Self-regulatory purpose ${ }^{b}$ & $\begin{array}{l}\text { "Doing math HW helps develop good discipline" } \\
\text { "Doing math HW helps develop a sense of responsibility" } \\
\text { "Doing math HW helps me learn to work independently" }\end{array}$ & .85 & .85 \\
\hline Approval-seeking purpose ${ }^{\mathrm{b}}$ & $\begin{array}{l}\text { "Doing math HW brings me family approval" } \\
\text { "Doing math HW brings me teacher approval" } \\
\text { "Doing math HW brings me approval from classmates" }\end{array}$ & .89 & .89 \\
\hline Mastery-approach ${ }^{\mathrm{c}}$ & $\begin{array}{l}\text { "I want to learn as much as possible in math HW" } \\
\text { "I prefer math HW that really challenges me so I can learn new things" } \\
\text { "The most important thing for me is trying to understand math HW as thoroughly as possible" } \\
\text { "Understand math is important to me" }\end{array}$ & .86 & .86 \\
\hline Performance-approach $^{\mathrm{c}}$ & $\begin{array}{l}\text { "It is important for me to do better than other students" } \\
\text { "My goal in doing math HW is to get a better grade than most of the other students" } \\
\text { "I want to do well in math HW to show my ability to my family, friends, teachers, or others" }\end{array}$ & .76 & .76 \\
\hline Homework interest ${ }^{\mathrm{d}}$ & $\begin{array}{l}\text { "I look forward to math } \mathrm{HW}^{\mathrm{d}} \text { ", } \\
\text { "Math HW is fun }{ }^{\mathrm{d}}, \\
\text { "I enjoy math } \mathrm{HW}^{\mathrm{d}} \text {, } \\
\text { "How do you think about math HW in general"?" }\end{array}$ & .91 & .91 \\
\hline Homework quality ${ }^{\mathrm{b}}$ & $\begin{array}{l}\text { "Our math teacher knows what HW to give us so that we understand the material covered in } \\
\text { the lesson" } \\
\text { "Our math HW assignments really help us to understand our math lessons" } \\
\text { "Our math teacher almost always chooses HW assignments really well" } \\
\text { "Our math HW assignments are always well integrated into the lessons" }\end{array}$ & .87 & .87 \\
\hline Help seeking ${ }^{c}$ & $\begin{array}{l}\text { "I ask my teacher to clarify math concepts I don't understand well" } \\
\text { "When I don't understand my math HW, I ask a classmate for help" } \\
\text { "When I don't understand my math HW, I ask a knowledgeable friend for help" } \\
\text { "When I don't understand my math HW, I ask my parents or other family members for help" } \\
\text { "I try to identify other sources where I can get help if necessary (e.g., a librarian)" }\end{array}$ & .75 & .76 \\
\hline Homework environment management $\mathrm{f}^{\mathrm{f}}$ & $\begin{array}{l}\text { "Locate the materials I need for my math HW" } \\
\text { "Find a quiet area" } \\
\text { "Remove things from the table" } \\
\text { "Make enough space for me to work" } \\
\text { "Turn off the TV" }\end{array}$ & .72 & .73 \\
\hline
\end{tabular}

HW = homework

${ }^{a}$ None (1), some (2), about half (3), most (4), all (5)

${ }^{\mathrm{b}}$ Strongly disagree (1), disagree (2), agree (3), strongly agree (4)

${ }^{\mathrm{c}}$ Not at all true of me (1) to very true of me (7)

${ }^{\mathrm{d}}$ Strongly disagree (1), disagree (2), neither disagree nor agree (3), agree (4), strongly agree (5)

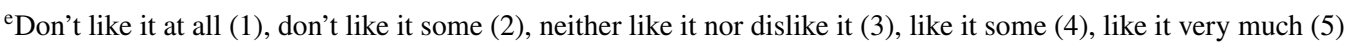

${ }^{\mathrm{f}} \mathrm{Never}(1)$, rarely (2), sometimes (3), often (4), routinely (5)

Time Spent Watching TV Students reported how much time they spend watching TV on a typical weekday. Possible responses included: none (1), half hour or less (2), more than half to $1 \mathrm{~h}(3)$, more than 1 to $1.5 \mathrm{~h}(4)$, more than 1.5 to $2 h(5)$, more than 2 to $2.5 h$ (6), more than 2.5 to $3 h$ (7), and more than $3 h(8)$. Time spent watching TV as a variable was created by transforming each option to the midpoint (e.g., $2=15 \mathrm{~min}$ ).
Homework Environment Management Informed by the self-regulation perspective (Pintrich, 2004; Wolters, 2003) and the relevant homework research (Xu, 2012; Yang \& Tu, 2020; Yang \& Xu, 2015), this scale contained five items to measure students' initiatives in arranging or structuring their study environment for doing math homework (Yang \& Xu, 2015; Xu, 2015). Specifically, students were asked: "How do you start your math homework?" This question was followed 
by the following five items, including (a) "locate the materials I need for my math homework", (b) "find a quiet area", (d) "remove things from the table", (d) "make enough space for me to work", and (e) "turn off the TV". For our current investigation, confirmatory factor analysis revealed that homework environment management could be treated as a unitary construct $(\mathrm{CFI}=.993$; $\mathrm{TLI}=.983$; $\mathrm{SRMR}=.017$; RMSEA $=.047 ; 90 \% \mathrm{CI}=.032, .063)$. Additionally, in line with theoretical predications (Pintrich, 2004; Puzziferro, 2008), students' management of homework environment was positively associated with math achievement measured at the end of the school year $(r=.26, p<.001)$.

\section{Data Analysis}

Descriptive statistics and Pearson correlations of all measures were presented first. As participants were nested in classrooms, multilevel analyses were conducted to appropriately take care of issues related to the nested data structure (Raudenbush \& Bryk, 2002). Multilevel analyses were carried out applying HLM 6.08. Following the recommendation by Trautwein et al. (2006), all continuous variables were standardized $(M=0$, $S D=1)$ in SPSS 25. Hence, the resulting regression weights are equivalent with the standardized weights based on multiple regression procedures (Trautwein et al., 2006).

Model 1 incorporated 14 student-level variables: background variables (gender, parent education, and prior knowledge), homework characteristics (interest and quality), adult support and monitoring (teacher feedback and family help), homework purposes (academic, self-regulatory, and approval-seeking), goal orientations (mastery- and performance-approaches), and contextual control (help seeking and time on TV). Additionally, Model 2 introduced four class-level variables (homework quality, homework interest, teacher feedback, and parent education).

As we did not have hypotheses with respect to the predictive power of the individual-level predictors across classes, all models were random-intercept models (Raudenbush \& Bryk, 2002). We centered four class-level variables at the group mean, to disentangle individual effects from contextual effects (Raudenbush \& Bryk, 2002). We used full maximum likelihood in our multilevel models. Missing values for our study were low (ranging from .00\% to $3.35 \%$ ) and were imputed by applying the expectation-maximization algorithm.

\section{Results}

\section{Descriptive Statistics}

Responses were approximately normally distributed (i.e., values $<2.00$ ), with kurtosis values varying from -1.16 to
1.69 (median $=-.19)$, and skewness values varying from -.67 to 1.60 (median $=-.12$ ). Table 2 contains means and standard deviations of all measures, as well as Pearson correlations between predictor variables and students' management of homework environment. Students' management of homework environment was significantly associated with all eighteen predictor variables.

\section{Multilevel Analyses}

We conducted the null model to partition the total variance of the dependent variable (i.e., students' management of homework environment) into within- and between-class components. Findings revealed that $13.2 \%$ of the variance in students' management of homework environment was at the class level. The deviance statistics for the null model was 8261.96 (3 parameters).

Model 1 included 14 variables at the student level (Table 3). The deviance statistics for this model was 7674.59 (17 parameters). We applied the likelihood ratio test to compare it to the null model. Our findings showed that Model 1 resulted in a significantly improved fit when compared with the null model $\left[\chi^{2}(14)=587.37, p<.001\right]$. Model 1 accounted for $17.3 \%$ of the individual-level variance in management of homework environment and explained $31.4 \%$ of the class-level variance. Students' management of homework environment was related positively to prior achievement, homework interest, perceived homework quality, family help, teacher feedback, academic and self-regulatory purposes, mastery-approach, and help seeking. Meanwhile, it was related negatively to time spent watching TV. Males (compared with females) made less effort to arrange their homework environment.

Model 2 introduced four class-level variables. The deviance statistics for this model was 7659.20 (21 parameters). We used the likelihood ratio test to compare Model 2 to Model 1 Model 2 yielded a significantly better fit than Model $1\left[\chi^{2}(4)=15.40, p<.01\right]$. Our findings indicated that Model 2 accounted for an additional $15.7 \%$ of the variance in management of homework environment at the class level.

Overall, Model 2 explained $17.3 \%$ of the student-level variance in management of homework environment, and $47.1 \%$ of the class-level variance. Students' management of homework environment was associated positively with prior achievement, homework interest, perceived homework quality, family help, teacher feedback, academic and selfregulatory purposes, mastery-approach, and help seeking. Meanwhile, management of homework environment was associated negatively with time spent watching TV. Furthermore, compared with females, males made less effort to arrange their homework environment. Finally, students' management of homework environment was associated positively with perceived homework quality at the class level. 


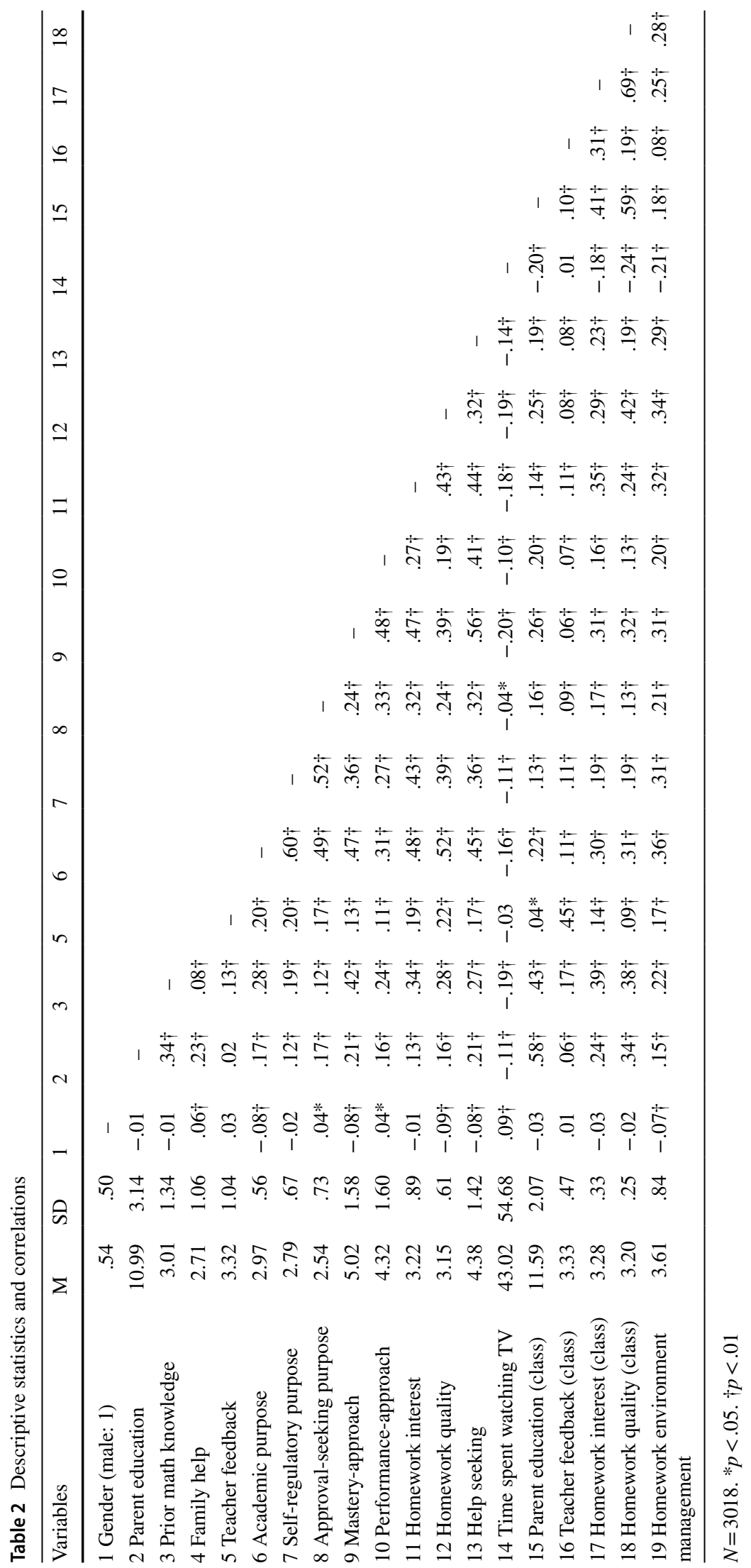


Table 3 Multilevel findings for homework environment management

\begin{tabular}{|c|c|c|c|c|c|}
\hline \multirow[t]{2}{*}{ Model Predictor } & & \multicolumn{2}{|l|}{ Model 1} & \multicolumn{2}{|l|}{ Model 2} \\
\hline & & $b$ & $S E$ & $b$ & $S E$ \\
\hline \multicolumn{6}{|l|}{ Student level } \\
\hline & Gender (female: 0 , male: 1 ) & $-.12 * *$ & .03 & $-.12 * *$ & .03 \\
\hline & Parent education & .01 & .02 & .01 & .02 \\
\hline & Prior math knowledge & $.05^{*}$ & .02 & $.04 *$ & .02 \\
\hline & Family help & $.07 * *$ & .02 & $.07 * *$ & .02 \\
\hline & Teacher feedback & $.07 * *$ & .02 & $.07 * *$ & .02 \\
\hline & Academic purpose & $.10 * * *$ & .03 & $.09 * *$ & .03 \\
\hline & Self-regulatory purpose & $.09 * * *$ & .02 & $.09 * * *$ & .02 \\
\hline & Approval-seeking purpose & -.01 & .02 & -.01 & .02 \\
\hline & Mastery-approach & $.05 *$ & .02 & $.05^{*}$ & .02 \\
\hline & Performance-approach & .01 & .02 & .02 & .02 \\
\hline & Homework interest & $.06 * *$ & .02 & $.07 * *$ & .02 \\
\hline & Perceived homework quality & $.09 * * *$ & .02 & $.09 * * *$ & .02 \\
\hline & Help seeking & $.05^{*}$ & .02 & $.05^{*}$ & .02 \\
\hline & Time spent watching TV & $-.11^{* * *}$ & .02 & $-.10^{* * *}$ & .02 \\
\hline \multicolumn{6}{|l|}{ Class level } \\
\hline & Parent education & & & -.12 & .06 \\
\hline & Teacher feedback & & & .05 & .08 \\
\hline & Homework interest & & & .02 & .16 \\
\hline & Perceived homework quality & & & $.37 *$ & .15 \\
\hline$R^{2}$ student level & & $17.3 \%$ & & $17.3 \%$ & \\
\hline$R^{2}$ class level & & $31.4 \%$ & & $47.1 \%$ & \\
\hline$R^{2}$ total & & $19.2 \%$ & & $21.2 \%$ & \\
\hline Deviance statistics & & 7674.59 & & 7659.20 & \\
\hline Parameters & & 17 & & 21 & \\
\hline
\end{tabular}

$N=3018 . R^{2}=$ explained variance

${ }^{*} p<.05$. ** $p<.01$. *** $p<.001$

\section{Discussion}

\section{Summary of Result}

The current investigation tested empirical models of homework environment management that considers the six clusters of variables including background variables, homework characteristics, adult support and monitoring, task utility, goal orientations, and contextual control. Our results demonstrating that homework environment management was significantly associated with at least one variable from each of the six clusters lend empirical support to our models. These results illustrate the complexities of factors that influence homework environment management, something that has been largely absent in prior homework research. Specifically, management of homework environment was associated negatively with time spent watching TV, and positively with prior achievement, homework interest, perceived homework quality, family help, teacher feedback, academic purpose, self-regulatory purpose, mastery-approach, and help seeking. Furthermore, males managed their homework environment less frequently than females. Finally, homework environment management was related positively to homework quality at the class level (i.e., beyond its relationship at the student level).

\section{Interpretation}

The finding relating to gender difference favoring females is congruent with prior research on self-regulation literature, in which females tend to report greater use of environmental structuring (Cleary, 2006; Zimmerman \& Martinez-Pons, 1990). Yet, it is not congruent with the prior study of U.S. students that resulted in no gender difference in homework environment management (Xu, 2012). As environmental structuring may be influenced by achievement domain and cultural difference (Li, 2019; Pajares, 2002), part of this discrepancy is likely due to the domain-specific function (math) of the China result and the cross-domain function of the U.S. result. This discrepancy constitutes an important focus of future research. 
Our results demonstrating that students' management of homework environment was associated positively with prior math knowledge, family help, homework interest, and teacher feedback are congruent with the self-regulation perspective (Pintrich, 1999, 2004; Schunk, 2005; Zimmerman \& Martinez-Pons, 1990) and with the prior study with U.S. students (Xu, 2012). Also consistent with the results from a study on U.S. secondary students (Xu, 2012), our present study found that students' management of homework environment was negatively related to time spent watching $\mathrm{TV}$, but unrelated to parent education. These convergences suggest that these results may be applicable across cultural settings (China vs. U.S.) and achievement domains (management of math homework environment vs. homework environment management in general). Interestingly, what parents do (i.e., homework help in the cluster of adult monitoring) appears to matter more to students' homework environment management than what parents have (i.e., education level in the cluster of background variables), after controlling other clusters of variables in our multilevel analyses.

In a prior study, Xu (2012) found that students' management of their homework environment was related positively to learning-oriented purpose, where learning-oriented purpose consisted of items regarding both academic purpose and self-regulatory purpose. Thus, the present investigation took a step forward, by revealing that management of homework environment was positively associated with two different homework purposes, academic purpose and selfregulatory purpose.

Our results demonstrating that homework environment was positively related to mastery-approach, but not performance-approach are in accordance with the self-regulation perspective; the adoption of mastery approach facilitates self-regulated learning (Pintrich, 1999). They are further in line with the extant literature on goal orientations (Cellar et al., 2011; Payne et al., 2007; Scherrer et al., 2020) demonstrating that mastery-approach is more adaptive and has consistent positive relations with desirable aspects of self-regulation (e.g., self-monitoring), whereas the corresponding relationships between performance-approach and aspects of self-regulation are more variable and weakly related. One explanation is that students who are motivated to show competence to others (performance-approach) are likely to take self-regulatory initiatives (e.g., managing and controlling study environment). Yet, performanceapproach may also result in anxiety and distraction, thereby diminishing the positive effect of this approach on self-regulatory initiatives (Cellar et al., 2011). This is particularly true for math homework, since math anxiety is a common issue among students across different countries (Hong et al., 2015; Lee, 2009). Taken together, as none of the previous research, to our knowledge, has explicitly linked goal orientations to study environment management, our present study extends prior research in the context of homework environment management.

The finding regarding the positive influence of help seeking on students' management of homework environment is in accordance with the model by Pintrich (2004). Students often do not have direct control over their study environment, therefore their efforts to procure help from others in the environment are likely to facilitate their s' homework environment management. This is further congruent with the result of a prior study with undergraduates, in which the management of study environment in online groupwork was associated positively with help seeking (Du et al., 2015). Given that Du et al. (2015) investigated online groupwork of U.S. undergraduates whereas the current study focused on math homework assigned to Chinese middle school students, this convergence suggests that the linkage between environment management and help seeking may exist across cultural settings (U.S. vs. China), school levels (middle school vs. college), learning environments (face-to-face vs. online), or the nature of the task (individually-oriented homework vs. collaborative groupwork).

Previous research results suggest that perceived homework quality is positively associated with homework motivation, effort, self-regulation, and study habits (Trautwein \& Lüdtke, 2009; Stoeger \& Ziegler, 2011; Xu, 2016). These findings imply that when students perceive their assignments to be of a higher quality, they are more likely to consider them valuable and beneficial, and take more initiative in arranging, managing, controlling, regulating, or manipulating their environment to complete their homework. Hence, by explicitly linking homework quality to homework environment management, our present investigation has provided empirical support to the hypothesis that management of homework environment is positively associated with homework quality both at the class and individual level.

Whereas congruent with the call for applying a multilevel, domain-specific approach to homework (Trautwein et al., 2006; Yang et al., 2016), the current investigation took one important step forward by studying students' management of math homework environment. Indeed, null model indicated that there was a substantial variance in homework environment management at the class variance (i.e., 13.2\%), thereby providing empirical support for the multilevel nature of students' management of homework environment.

Specifically, our multilevel results relating to teacher feedback (i.e., homework environment management was positively related to teacher feedback at the student level, yet not at the class level) is congruent with previous research $(\mathrm{Xu}, 2012)$. One explanation is that students are more likely to benefit from their teachers' feedback when 
it is more individualized and more personally relevant. As a result, the linkage between teacher feedback and homework environment management may be less apparent at the class level.

In a previous study (Xu, 2012) excluding perceived homework quality, students' management of homework environment was positively correlated with homework interest both at the student and class levels. By comparison, in the current study including homework quality, homework environment management was positively related to homework interest at the student level but unrelated at the class level. A plausible explanation is that merely making homework assignments more interesting for classes might undercut the initiatives of some students in these classes to manage homework independently (Xu \& Wu, 2013). Another likely explanation is that, compared with homework interest and teacher feedback, perceived homework quality plays a more prominent role in homework environment management, particularly given that perceived homework quality was the only significant class-level predictor in our present study. This is an intriguing hypothesis for future research.

\section{Practical Implications}

In line with related findings from a study with U.S. students (Xu, 2012), our findings that management of homework environment was positively related to teacher feedback and family help imply that adult support and monitoring can influence students' management of homework environment well into the middle school. Hence, it is important for schools to provide relevant support and guidance regarding family homework involvement during the middle school years, as parents of middle school children are often more concerned with assisting children to develop good study habits than with managing the content of homework assignments (Reetz, 1991; Xu, 2004). Yet, middle schools (compared with elementary schools) tend to devote less attention to the role of homework in developing good study habits (Muhlenbruck et al., 2000; Xu et al., 2014). This type of support and guidance is particularly important for parents during a pandemic (such as the SARS-CoV-2), as helping with homework (e.g., monitoring and checking) becomes one of the major concerns and stressors for parents (Cui et al., 2021; Duraku \& Hoxha, 2020).

Given that homework environment management was positively related to homework characteristics (i.e., homework quality and interest), there is a need to devote close attention to homework quality, by carefully designing homework assignments for students to perceive that they would benefit from doing homework (e.g., regarding the relevance of homework to understand and master the core subject material covered in lessons). Furthermore, there is a need to devote greater attention to students' interest (e.g., activity and content interest when developing homework assignments; Corno \& Xu, 2004: Yang et al., 2016). These recommendations are timely and important, as recent studies have found that two emerging issues regarding homework quality and interest during the SARS-CoV-2 pandemic are the ambiguity of homework and the decline of students' interest in homework (Cui et al., 2021; Duraku \& Hoxha, 2020; Zaccoletti et al., 2020).

Furthermore, our results concerning mastery-approach, academic purpose, and self-regulatory purpose suggest that the students' goals and purposes for doing homework have positive influences on their management of homework environment, in addition to and beyond teacher and family influences (i.e., teacher feedback, family help, homework interest, and homework quality). This implication follows the idea that students will view their homework as meaningful and valuable if they consider even some of the homework assignments as means for narrowing important gaps in their academic experience (Corno, 2000). Consequently, they will be more likely to apply self-regulatory strategies $(\mathrm{Xu}, 2008)$. This is further substantiated by our finding that self-regulatory strategies such as help seeking were positively related to homework environment management. Hence, it would be appropriate to pay close attention to the voices of students (e.g., regarding what homework and homework environment management mean for them), so that families and teachers can make more coordinated efforts to make homework environment management more manageable for students. This is particularly important, as some aspects of the homework environment (e.g., phone calls and the presence of siblings) are out of their control (Xu \& Corno, 2003), and as the SARS-CoV-2 pandemic presents an unprecedented challenge for many students and their families to arrange and manage their homework environment (Duraku \& Hoxha, 2020; Van Lancker \& Parolin, 2020; Zaccoletti et al., 2020).

\section{Strengths, Limitations, and Further Investigation}

Guided by the self-regulation perspective (Cleary, 2006; Pintrich, 2004; Schunk, 2005; Wolters, 2011; Zimmerman, 2008) and previous studies (Xu, 2012; Xu \& Corno, 2006; Yang \& Tu, 2020), the present investigation applied multilevel models to explicitly link students' management of homework environment to the six clusters of variables using a large sample of Chinese students. Specifically, it extended existing research by (a) revealing that management of homework environment was positively associated with mastery-approach, help seeking, and homework quality, and by (b) suggesting that homework quality (compared with homework interest) may play a more important role in homework environment management. 
Our current investigation has several limitations. First, it was based on self-reports from a cross-sectional survey (except for prior math knowledge). Thus, it would be beneficial to include multiple data sources (e.g., teacher rating and observation) and to conduct longitudinal research (e.g., cross-lagged panel design) to study how these clusters of variables may influence students' management of homework environment over time. Although much care was taken to incorporate the six clusters of variables informed by the selfregulation perspective (e.g., Pintrich, 1999, 2004; Zimmerman, 2008) and relevant homework studies (Xu, 2012; Xu \& Corno, 2006), additional predictors may have had affected students' homework environment management (e.g., parental aspirations and expectations). Hence, there is a need to pay greater attention to the relevant variables in future research on homework environment management.

It would be important to continue this line of investigation in subsequent research, as regulation of study environment has not commonly been examined separately from other regulatory strategies (Du et al., 2015; Wolters, 2003). It would be informative to investigate the six clusters of variables identified in our study (e.g., mastery-approach, help seeking, and perceived homework quality) in different domains (e.g., foreign language).Additionally, as our results regarding several variables (teacher feedback, family help, homework interest, and homework purpose) are consistent with a previous study with U.S. students (Xu, 2012), there is a need to investigate causal hypotheses by explicitly testing the influences of the variables such as teacher feedback (or homework quality) on students' management of homework environment. Finally, given that recent studies have explored personal learning environments due to the proliferation of information and communication technologies (Chaves-Barboza \& Rodríguez-Miranda, 2017; García-Martínez et al., 2021), and given that increasingly more university instructors have incorporated online homework in their courses (Magalhães et al., 2020; Xu et al., 2019), it would be important to examine students' management of personal learning environments while completing online homework.

Supplementary Information The online version contains supplementary material available at https://doi.org/10.1007/s12144-021-02596-5.

Data Availability The data supporting the findings of the current investigation are available from the corresponding author upon reasonable request.

\section{Declarations}

Conflict of Interest The author states no conflict of interest.

Human Rights This investigation was in accordance with the ethical standards of the institutional and national research committee, and with the tenets of Helsinki declaration.
Informed Consent Informed consent/assent was obtained from each participant in the current investigation.

\section{References}

Bao, W. (2020). COVID-19 and online teaching in higher education: A case study of Peking University. Human Behavior and Emerging Technologies, 2(2), 113-115. https://doi.org/10.1002/ hbe2.191

Beaunoyer, E., Dupéré, S., \& Guitton, M. J. (2020). COVID-19 and digital inequalities: Reciprocal impacts and mitigation strategies. Computers in Human Behavior, 111, 106424. https://doi. org/10.1016/j.chb.2020.106424

Bempechat, J. (2019). The case for (quality) homework: Why it improves learning, and how parents can help. Education Next, 19(1), 36-44.

Berger, J. L., \& Karabenick, S. A. (2011). Motivation and students' use of learning strategies: Evidence of unidirectional effects in mathematics classrooms. Learning and Instruction, 21(3), 416-428. https://doi.org/10.1016/j.learninstruc.2010.06.002

Brown, G. T., Peterson, E. R., \& Yao, E. S. (2016). Student conceptions of feedback: Impact on self-regulation, self-efficacy, and academic achievement. British Journal of Educational Psychology, 86(4), 606-629. https://doi.org/10.1111/bjep.12126

Cellar, D. F., Stuhlmacher, A. F., Young, S. K., Fisher, D. M., Adair, C. K., Haynes, S., Twichell, E., Arnold, K. A., Royer, K., Dunning, B. L., \& Riester, D. (2011). Trait goal orientation, selfregulation, and performance: A meta-analysis. Journal of Business and Psychology, 26(4), 467-483. https://doi.org/10.1007/ s10869-010-9201-6

Chaves-Barboza, E., \& Rodríguez-Miranda, L. (2017). Reliability and validity analysis of a questionnaire on personal learning environments (PLE). Ensayos Pedagógicos, 13(1), 71-106. https://doi.org/10.15359/rep.13-1.4.

Cleary, T. J. (2006). The development and validation of the self-regulation strategy inventory-Self-report. Journal of School Psychology, 44(4), 307-322. https://doi.org/10.1016/j.jsp.2006.05.002

Cooper, H. (1989). Homework. Longman.

Cooper, C. A., \& Corpus, J. H. (2009). Learners' developing knowledge of strategies for regulating motivation. Journal of Applied Developmental Psychology, 30(4), 525-536. https://doi.org/10. 1016/j.appdev.2008.12.032

Cooper, H., Lindsay, J. J., Nye, B., \& Greathouse, S. (1998). Relationships among attitudes about homework, amount of homework assigned and completed, and student achievement. Journal of Educational Psychology, 90(1), 70-83. https://doi.org/10. 1037/0022-0663.90.1.70

Corno, L. (2000). Looking at homework differently. Elementary School Journal, 100(5), 529-548. https://doi.org/10.1086/499654

Corno, L., \& Mandinach, E. B. (2004). What we have learned about student engagement in the past twenty years. In D. M. McInerney \& S. V. Etten (Eds.), Big theories revisited: Vol. 4. Research on sociocultural influences on motivation and learning ( $p p$. 299-328) Information Age.

Corno, L., \& Xu, J. (2004). Doing homework as the job of childhood. Theory Into Practice, 43(3), 227-233. https://doi.org/10.1207/ s15430421tip4303 9

Cui, S., Zhang, C., Wang, S., Zhang, X., Wang, L., Zhang, L., et al. (2021). Experiences and attitudes of elementary school students and their parents toward online learning in China during the COVID-19 pandemic: Questionnaire study. Journal of Medical Internet Research, 23(5), e24496. https://doi.org/10.2196/24496 
DeShon, R. P., \& Gillespie, J. Z. (2005). A motivated action theory account of goal orientation. Journal of Applied Psychology, 90(6), 1096-1127. https://doi.org/10.1037/0021-9010.90.6.1096

$\mathrm{Du}, \mathrm{J}$. (2016). Predictors for Chinese students' management of study environment in online groupwork. Educational Psychology, 36(9), 1614-1630. https://doi.org/10.1080/01443410.2015.1036008

Du, J., Xu, J., \& Fan, X. (2015). Investigating factors that influence students' management of study environment in online collaborative groupwork. Research Papers in Education, 30(4), 451-468. https://doi.org/10.1080/02671522.2014.940373

Du, J., Xu, J., \& Fan, X. (2016). Investigating factors that influence students' help seeking in math homework: A multilevel analysis. Learning and Individual Differences, 48, 29-35. https://doi.org/ 10.1016/j.lindif.2016.03.002

Duncan, T. G., \& McKeachie, W. J. (2005). The making of the motivated strategies for learning questionnaire. Educational Psychologist, 40(2), 117-128. https://doi.org/10.1207/s15326985e p4002_6

Duraku, Z. H., \& Hoxha, L. (2020). The impact of COVID-19 on education and on the well-being of teachers, parents, and students: Challenges related to remote (online) learning and opportunities for advancing the quality of education. Retrieved online from https://www.researchgate.net/publication/341297812.

Fan, H., Xu, J., Cai, Z., He, J., \& Fan, X. (2017). Homework and students' achievement in math and science: A 30-year meta-analysis, 1986-2015. Educational Research Review, 20, 35-54. https://doi. org/10.1016/j.edurev.2016.11.003

García-Martínez, J. A., González-Sanmamed, M., \& Muñoz-Carril, P. C. (2021). Validation of the activities' scale in higher education students' personal learninng environments. Psicothema, 33(2), 320-327. https://doi.org/10.7334/psicothema2020.259

Hagger, M. S., Wood, C., Stiff, C., \& Chatzisarantis, N. L. D. (2010). Ego depletion and the strength model of self-control: A metaanalysis. Psychological Bulletin, 136(4), 495-525. https://doi.org/ 10.1037/a0019486

Hong, E., Mason, E., Peng, Y., \& Lee, N. (2015). Effects of homework motivation and worry anxiety on homework achievement in mathematics and English. Educational Research and Evaluation, 21(7-8), 491-514. https://doi.org/10.1080/13803611.2015. 1131721

Karabenick, S. A. (2003). Seeking help in large college classes: A person-centered approach. Contemporary Educational Psychology, 28(1), 37-58. https://doi.org/10.1016/S0361-476X(02)00012-7

Kitsantas, A., \& Zimmerman, B. J. (2009). College students' homework and academic achievement: The mediating role of self-regulatory beliefs. Metacognition and Learning, 4(2), 97-110. https:// doi.org/10.1007/s11409-008-9028-y

Kitsantas, A., Cheema, J., \& Ware, H. W. (2011). Mathematics achievement: The role of homework and self-efficacy beliefs. Journal of Advanced Academics, 22(2), 310-339. https://doi.org/10.1177/ $1932202 X 1102200206$

Lee, J. (2009). Universals and specifics of math self-concept, math self-efficacy, and math anxiety across 41 PISA 2003 participating countries. Learning and Individual Differences, 19(3), 355-365. https://doi.org/10.1016/j.lindif.2008.10.009

Lee, S. Y., \& Brand, J. L. (2010). Can personal control over the physical environment ease distractions in office workplaces? Ergonomics, 53(3), 324-335. https://doi.org/10.1080/00140130903389019

León, J., Núñez, J. L., \& Liew, J. (2015). Self-determination and STEM education: Effects of autonomy, motivation, and self-regulated learning on high school math achievement. Learning and Individual Differences, 43, 156-163. https://doi.org/10.1016/j.lindif. 2015.08.017

Li, K. (2019). MOOC learners' demographics, self-regulated learning strategy, perceived learning and satisfaction: A structural equation modeling approach. Computers \& Education, 132, 16-30. https:// doi.org/10.1016/j.compedu.2019.01.003

Maas, C. J., \& Hox, J. J. (2005). Sufficient sample sizes for multilevel modeling. Methodology, 1(3), 86-92. https://doi.org/10.1027/ 1614-2241.1.3.86

Magalhães, P., Ferreira, D., Cunha, J., \& Rosário, P. (2020). Online vs traditional homework: A systematic review on the benefits to students' performance. Computers \& Education, 152, 103869. https://doi.org/10.1016/j.compedu.2020.103869

Marsh, H. W., Pekrun, R., Lichtenfeld, S., Guo, J., Arens, A. K., \& Murayama, K. (2016). Breaking the double-edged sword of effort/ trying hard: Developmental equilibrium and longitudinal relations among effort, achievement, and academic self-concept. Developmental Psychology, 52(8), 1273-1290. https://doi.org/10.1037/ $\operatorname{dev} 0000146$

Muhlenbruck, L., Cooper, H., Nye, B., \& Lindsey, J. J. (2000). Homework and achievement: Explaining the different strengths of relation at the elementary and secondary school levels. Social Psychology of Education, 3(4), 295-317. https://doi.org/10.1023/A: 1009680513901

Pajares, F. (2002). Gender and perceived self-efficacy in self-regulated learning. Theory Into Practice, 41(2), 116-125. https://doi.org/10. 1207/s15430421tip4102_8

Payne, S. C., Youngcourt, S. S., \& Beaubien, J. M. (2007). A metaanalytic examination of the goal orientation nomological net. Journal of Applied Psychology, 92(1), 128-150. https://doi.org/ 10.1037/0021-9010.92.1.128

Pintrich, P. R. (1999). The role of motivation in promoting and sustaining self-regulated learning. International Journal of Educational Research, 31(6), 459-470. https://doi.org/10.1016/S08830355(99)00015-4

Pintrich, P. R. (2000). The role of goal orientation in self-regulated learning. In M. Boekaerts, P. R. Pintrich, \& M. Zeidner (Eds.), Handbook of self-regulation (pp. 451-502). Academic Press.

Pintrich, P. R. (2004). A conceptual framework for assessing motivation and self-regulated learning in college students. Educational Psychology Review, 16(4), 385-407. https://doi.org/10.1007/ s10648-004-0006-x

Postigo, Á., Cuesta, M., Fernández-Alonso, R., García-Cueto, E., \& Muñiz, J. (2021). Academic grit modulates school performance evolution over time: A latent transition analysis. Revista de Psicodidáctica, 26, 87-95. https://doi.org/10.1016/j.psicoe.2021.03.001

Purdie, N., \& Hattie, J. (1996). Cultural differences in the use of strategies for self-regulated learning. American Educational Research Journal, 33(4), 845-871. https://doi.org/10.3102/0002831203 3004845

Puzziferro, M. (2008). Online technologies self-efficacy and selfregulated learning as predictors of final grade and satisfaction in college-level online courses. Amerrican Journal of Distance Education, 22(2), 72-89. https://doi.org/10.1080/0892364080 2039024

Raudenbush, S., \& Bryk, A. S. (2002). Hierarchical linear models: Applications and data analysis (2nd ed.). Sage.

Reetz, L. J. (1991). Parental perceptions of homework. Rural Educator, 12(2), 14-19.

Rosário, P., Núñez, J. C., Vallejo, G., Nunes, T., Cunha, J., Fuentes, S., \& Valle, A. (2018). Homework purposes, homework behaviors, and academic achievement. Examining the mediating role of students' perceived homework quality. Contemporary Educational Psychology, 53, 168-180. https://doi.org/10.1016/j.cedps ych.2018.04.001

Samani, S. A., Rasid, S. Z. A., \& Sofian, S. (2017). The influence of personal control and environmental distraction in open-plan offices on creative outcome. Performance Improvement Quarterly, 30(1), 5-28. https://doi.org/10.1002/piq.21239 
Scherrer, V., Preckel, F., Schmidt, I., \& Elliot, A. J. (2020). Development of achievement goals and their relation to academic interest and achievement in adolescence: A review of the literature and two longitudinal studies. Developmental Psychology, 56(4), 795-814. https://doi.org/10.1037/dev0000898

Schunk, D. H. (2005). Self-regulated learning: The educational legacy of Paul R. Pintrich. Educational Psychologist, 40(2), 85-94. https://doi.org/10.1207/s15326985ep4002_3

Sitzmann, T., \& Ely, K. (2011). A meta-analysis of self-regulated learning in work-related training and educational attainment: What we know and where we need to go. Psychological Bulletin, 137(3), 421-442. https://doi.org/10.1037/a0022777

Stoeger, H., \& Ziegler, A. (2011). Self-regulatory training through elementary-school students' homework completion. In B. J. Zimmerman \& D. H. Schunk's (Eds.), Handbook of self-regulation of learning and performance (pp. 87-101). Routledge.

Sun, M., Du, J., Xu, J., \& Liu, F. (2019). Homework goal orientation scale: Measurement invariance and latent mean differences across gender and grade level. Psychology in the Schools, 56(3), 465-477. https://doi.org/10.1002/pits.22206

Sun, M., Du, J., \& Xu, J. (2020). Math homework purpose scale: Measurement invariance and latent mean differences across gender. Swiss Journal of Psychology, 79(2), 47-54. https://doi.org/10. 1024/1421-0185/a000234

Sun, M., Du, J., \& Xu, J. (2021). Are homework purposes and student achievement reciprocally related? A longitudinal study. Current Psychology, 40(10), 4945-4956. https://doi.org/10.1007/ s12144-019-00447-y

Tang, X., Wang, M. T., Parada, F., \& Salmela-Aro, K. (2021). Putting the goal back into grit: Academic goal commitment, grit, and academic achievement. Journal of Youth and Adolescence, 50, 470-484. https://doi.org/10.1007/s10964-020-01348-1

Tas, Y., Sungur, S., \& Oztekin, C. (2016). Development and validation of science homework scale for middle-school students. International Journal of Science and Mathematics Education, 14(3), 417-444. https://doi.org/10.1007/s10763-014-9582-5

Trautwein, U., \& Lüdtke, O. (2009). Predicting homework motivation and homework effort in six school subjects: The role of person and family characteristics, classroom factors, and school track. Learning and Instruction, 19(3), 243-258. https://doi.org/10. 1016/j.learninstruc.2008.05.001

Trautwein, U., Lüdtke, O., Schnyder, I., \& Niggli, A. (2006). Predicting homework effort: Support for a domain-specific, multilevel homework model. Journal of Educational Psychology, 98(2), 438-456. https://doi.org/10.1037/0022-0663.98.2.438

Van Lancker, W., \& Parolin, Z. (2020). COVID-19, school closures, and child poverty: A social crisis in the making. The Lancet Public Health, 5(5), 243-244. https://doi.org/10.1016/s2468-2667(20)30084-0

Wigfield, A., \& Cambria, J. (2010). Students' achievement values, goal orientations, and interest: Definitions, development, and relations to achievement outcomes. Developmental Review, 30(1), 1-35. https://doi.org/10.1016/j.dr.2009.12.001

Wigfield, A., Tonks, S., \& Eccles, J. S. (2004). Expectancy value theory in cross-cultural perspective. In D. M. McInerney \& S. V. Etten (Eds.), Big theories revisited: Vol. 4. Research on sociocultural influences on motivation and learning (pp. 165-198). Information Age.

Wolters, C. A. (1999). The relation between high school students' motivational regulation and their use of learning strategies, effort, and classroom performance. Learning and Individual Differences, 11(3), 281-299. https://doi.org/10.1016/S1041-6080(99)80004-1

Wolters, C. A. (2003). Regulation of motivation: Evaluating an underemphasized aspect of self-regulated learning. Educational Psychologist, 38(4), 189-204. https://doi.org/10.1207/S15326985E P3804_1
Wolters, C. A. (2011). Regulation of motivation: Contextual and social aspects. Teachers College Record, 113(2), 265-283.

$\mathrm{Xu}$, J. (2004). Family help and homework management in urban and rural secondary schools. Teachers College Record, 106(9), $1786-1803$.

$\mathrm{Xu}, \mathrm{J}$. (2008). Models of secondary students' interest in homework: A multilevel analysis. American Educational Research Journal, 45(4), 1180-1205. https://doi.org/10.3102/0002831208323276

$\mathrm{Xu}, \mathrm{J}$. (2010). Predicting homework distraction at the secondary school level: A multilevel analysis. Teachers College Record, 112(7), 1937-1970.

Xu, J. (2011). Homework purpose scale for middle school students: A validation study. Middle Grades Research Journal, 6(1), 1-14.

$\mathrm{Xu}$, J. (2012). Predicting students' homework environment management at the secondary school level. Educational Psychology, 32(2), 183-200. https://doi.org/10.1080/01443410.2011.635639

$\mathrm{Xu}, \mathrm{J}$. (2015). Investigating factors that influence conventional distraction and tech-related distraction in math homework. Computers \& Education, 81, 304-314. https://doi.org/10.1016/j.compedu. 2014.10.024

$\mathrm{Xu}, \mathrm{J}$. (2016). A study of the validity and reliability of the teacher homework involvement scale: A psychometric evaluation. Measurement, 93, 102-107. https://doi.org/10.1016/j.measurement. 2016.07.012

$\mathrm{Xu}$, J. (2021). Math homework purpose scale: Confirming the factor structure with high school students. Psychology in the Schools, 58(8), 1518-1530. https://doi.org/10.1002/pits.22507

Xu, J., \& Corno, L. (1998). Case studies of families doing third grade homework. Teachers College Record, 100(2), 402-436.

$\mathrm{Xu}$, J., \& Corno, L. (2003). Family help and homework management reported by middle school students. Elementary School Journal, 103(5), 503-518. https://doi.org/10.1086/499737

Xu, J., \& Corno, L. (2006). Gender, family help, and homework management reported by rural middle school students. Journal of Research in Rural Education, 21(2) Retrieved from http://cites eerx.ist.psu.edu/viewdoc/summary?doi=10.1.1.536.1737

Xu, J., \& Wu, H. (2013). Self-regulation of homework behavior: Homework management at the secondary school level. Journal of Educational Research, 106(1), 1-13. https://doi.org/10.1080/00220 671.2012.658457

Xu, J., Yuan, R., Xu, B., \& Xu, M. (2014). Modeling students' time management in math homework. Learning and Individual Differences, 34, 33-42. https://doi.org/10.1016/j.lindif.2014.05.011

Xu, J., Fan, X., \& Du, J. (2015). Homework Management Scale: Confirming the factor structure with middle school students in China. Psychology in the Schools, 52(4), 419-429. https://doi. org/10.1002/pits.21826

Xu, J., Fan, X., Du, J., \& Cai, Z. (2019). Homework expectancy value scale for undergraduates in online environments: Measurement invariance and latent mean differences across gender. European Journal of Psychological Assessment, 35(5), 666-673. https://doi. org/10.1027/1015-5759/a000455

Xu, J., Du, J., Cunha, J., \& Rosário, P. (2021). Student perceptions of homework quality, autonomy support, effort, and math achievement: Testing models of reciprocal effects. Teaching and Teacher Education, 108, 103508. https://doi.org/10.1016/j.tate.2021. 103508

Yang, F., \& Tu, M. (2020). Self-regulation of homework behaviour: Relating grade, gender, and achievement to homework management. Educational Psychology, 40, 392-408. https://doi.org/10. 1080/01443410.2019.1674784

Yang, F., \& Xu, J. (2015). Examining the psychometric properties of the homework management scale for high school students in China. Journal of Psychoeducational Assessment, 33(3), 268-277. https://doi.org/10.1177/0734282914548326 
Yang, F., Xu, J., Tan, H., \& Liang, N. (2016). What keeps Chinese students motivated in doing math homework? An empirical investigation. Teachers College Record, 118(8), 1-26.

Zaccoletti, S., Camacho, A., Correia, N., Aguiar, C., Mason, L., Alves, R. A., \& Daniel, J. R. (2020). Parents' perceptions of student academic motivation during the COVID-19 lockdown: A crosscountry comparison. Frontiers in Psychology, 11, 592670. https:// doi.org/10.3389/fpsyg.2020.592670

Zimmerman, B. J. (1998). Academic studying and the development of personal skill: A self-regulatory perspective. Educational Psychologist, 33(2-3), 73-86. https://doi.org/10.1080/00461520. 1998.9653292

Zimmerman, B. J. (2008). Investigating self-regulation and motivation: Historical background, methodological developments, and future prospects. American Educational Research Journal, 45(1), 166-183. https://doi.org/10.3102/0002831207312909
Zimmerman, B. J., \& Kitsantas, A. (2005). Homework practices and academic achievement: The mediating role of self-efficacy and perceived responsibility beliefs. Contemporary Educational Psychology, 30(4), 397-417. https://doi.org/10.1016/j.cedpsych.2005. 05.003

Zimmerman, B. J., \& Martinez-Pons, M. (1990). Student differences in self-regulated learning: Relating grade, sex, and giftedness to self-efficacy and strategy use. Journal of Educational Psychology, 82(1), 51-59. https://doi.org/10.1037/0022-0663.82.1.51

Publisher's Note Springer Nature remains neutral with regard to jurisdictional claims in published maps and institutional affiliations. 